\title{
Lidar Observation Of Gravity And Tidal Waves In The Stratosphere And Mesosphere
}

\author{
Marie-Lise Chanin and Alain Hauchecorne
}

Service d'Aéronomie du CNRS, 91370 Verrières-le-Buisson, France

\begin{abstract}
Lidar measurements of atmospheric density and temperature in the altitude range 30-to $80 \mathrm{~km}$ have been performed during the last 2 years from the Observatory of Haute-Provence (latitude $44^{\circ} \mathrm{N}$, longitude, $6^{\circ} \mathrm{E}$ ). The potential of this technique for studying the middle atmospheric structure is presented and preliminary results on wave propagation are discussed. It is shown that wave-like structures are observed systematically in this height range. Fourier analysis indicates that most of the energy is transported by waves of vertical wavelengths on the order of 8 to $15 \mathrm{~km}$. The amplitude of the density variations is shown to follow a $\rho^{-1 / 2}$ law up to $70 \mathrm{~km}$. The characteristics of the observed density waves suggest that they are caused by a superposition of internal gravity waves propagating upward from the troposphere and a diurnal tide component in the range $30-50 \mathrm{~km}$. Such waves are able to induce quite significant perturbations in atmospheric density and therefore temperature on an hourly basis. The Lidar technique is able to monitor those variations for the first time from a ground station operating continuously.
\end{abstract}

\section{INTRODUCTION}

The atmospheric density profiles are expected to present wave-like structures due to gravity wave perturbations. Their characteristics have been calculated by means of perturbation theory [Hines, 1960] and have been observed by rocket [Favre et al., 1974; Phillbrick et al., 1974]. Calculation and experimental data are in satisfactory agreement; but, up to now, only rocket data have been available and only sporadically. Therefore it has been difficult to follow the wave propagation and to describe all its characteristics.

The results presented here by using Lidar sounding from the ground can be obtained on a continuous basis, offering the new possibility of studying the wave propagation and its consequences on the temperature and density of the middle atmosphere. In the Lidar method, the light from a laser pulse sent vertically through the atmosphere is backscattered by moleculres in the atmosphere or by any other particles which may be present in the laser beam path. This technique has been used for more than a decade with the purpose of measuring atmospheric parameters above $70 \mathrm{~km}$. Kent and Keenliside [1975] have reported what they interpret as evidence of tidal modes in the atmospheric density between 70 and $100 \mathrm{~km}$. However, most of the lidar results on wave propagation have been obtained between 80 and $100 \mathrm{~km}$ from the resonance backscatter from sodium atoms [Blamont et al., 1972; Kirchoff and Clemesha, 1973; Richter and Sechrist, 1979; Juramy et al., 1981]. The results presented here are obtained in the 30-80 $\mathrm{km}$ region and are therefore the first ones in this domain.

Over the last 2 years, density and temperature between 30 and $80 \mathrm{~km}$ have been measured from our Lidar stations at the Observatory of Haute Provence in France $\left(44^{\circ} \mathrm{N}, 6^{\circ} \mathrm{E}\right)$. As reported earlier, a comparison between lidar and rocket data showed the two methods to be compatible [Hauchecorne and Chanin [1980]. Since then, the quality of the data has increased, yielding either an improvement in accuracy or a reduction of the spatial or temporal resolution. We describe this technique and present preliminary results on wave propagation measurements.

Copyright ㅇ 1981 by the American Geophysical Union.

\section{SYSTEM DESCRIPTION}

For an atmosphere free of aerosols, the light backscattered by the atmosphere from a laser bean is due to Rayleigh scattering by atmospheric molecules, unless the emitted wavelength coincides with a resonance line of atmospheric constituents. To optimize the lidar system to measure neutral density we should take into account the $\lambda^{-4}$ variation of Rayleigh cross section, the energy per pulse of the laser, its repetition rate, and the quantum efficiency of the receiver at the laser wavelength. Rapidly evolving laser technology precludes a definitive answer for such an optimization, but at the present time the optimal spectral range appears to lie around $500 \mathrm{~nm}$.

In a first step, the atmospheric density profiles were obtained from the lidar station set up to study the mesospheric alkali atoms at the Observatory of Haute Provence. Two wavelengths were used corresponding to the sodium or lithium resonance at 589 and $670 \mathrm{~nm}$, respectively. The description of this lidar facility has been given in earlier publications [Megie and Blamont, 1977; Jegou et al., 1980] and is summarized in Table 1 . The altitude range is limited downward by a chopper designed for protection of the photomultiplier and upward by the signal-to-noise ratio. Most of the data have been obtained during nighttime and so are all the data used in this analysis. The extension to daytime is only recent and at the present time limited to a range of $50 \mathrm{~km}$. Recently, since November 1979 , the data have also been obtained with a new lidar station designed for tropospheric and stratospheric measurements and optimized for the detection of Rayleigh scattering. This station, set up alongside the first one, uses for density soundings the first harmonic of a Nd-Yag laser emitting 300 $\mathrm{mJ}$ at $530 \mathrm{~nm}$ with a $10 \mathrm{hz}$ repetition rate; the efficiency is then increased by a factor of 10 . In this station, described in Table 2 , the measurements are not limited downward below $30 \mathrm{~km}$, but, because of the presence of stratospheric aerosols, we have only considered, up to now, the data above $30 \mathrm{~km}$.

Lidar Measurements of Density and Temperature IN THE MIDDLE ATMOSPHERE: EXPERIMENTAL LIMITS

\section{AND ACCURACY}

In a previous article, [Hauchecorne and Chanin, 1980] the method to deduce atmospheric density from laser backscat- 
TABLE 1. Major System Parameters for the Lidar Used for Nighttime Mesospheric Studies at the Observatory of Haute Provence $\left(44^{\circ} \mathrm{N}, 6^{\circ} \mathrm{E}\right)$

\begin{tabular}{lcc}
\hline & System 1 & System 2 \\
\hline Wavelength & Emitter & \\
Energy & $589 \mathrm{~nm}$ & $670 \mathrm{~nm}$ \\
Linewidth & $1 \mathrm{~J} / \mathrm{pulse}$ & $0.8 \mathrm{~J} / \mathrm{pulse}$ \\
Pulse width & $8 \mathrm{pm}$ & $6 \mathrm{pm}$ \\
Repetition rate & $3 \mu \mathrm{S}$ & $3,5 \mu \mathrm{s}$ \\
Divergence & $0.5-0,1 \mathrm{~Hz}$ & $1-2 \mathrm{~Hz}$ \\
Divergence & $2 \times 10^{-3} \mathrm{rad}$ & $10^{-3} \mathrm{rad}$ \\
$\quad$ (after collimation) & $2 \times 10^{-4} \mathrm{rad}$ & $10^{-4} \mathrm{rad}$ \\
& & \\
Telescope diameter & Receiver & \\
Telescope area & $0.818 \mathrm{~m}$ & \\
Field of view & $0.515 \mathrm{~m}$ & \\
(for nighttime) & $5 \times 10^{-4} \mathrm{rad}$ \\
Bandwidth & $0.4 \mathrm{~nm}$ \\
Receiver gate & $8 \mu \mathrm{s}(1,2 \mathrm{~km}$ ) \\
\hline * Method: photon counting combined with analogical recording.
\end{tabular}

tered signal has been described. It should be pointed out that, due to the lack of an absolute calibration of the atmospheric transmission, the density profile needs to be fitted either to a theoretical model or to other experimental data. The reference used in this paper is the CIRA 1972 model that takes into account the seasonal variation. The fitting of the experimental data with this model is performed between 30 and $35 \mathrm{~km}$. The uncertainty of the density measurement is assumed to be the statistical standard error. Up to the altitude where the sky background becomes the same order of magnitude than the laser backscattered echo, the error bar (shaded area on the figures) represents 1 standard deviation and is given by the square root of the number of laser backscattered photons. In the near future a reduction of the field of view of the receiver will increase the range of the measurements. The height resolution for all the measurements presented here is either 0.6 or $1.2 \mathrm{~km}$, but a running average over 6 or 3 points has been performed to improve the accuracy, reducing then the resolution to $3.6 \mathrm{~km}$ (except in one case corresponding to Figure 4, where the smoothing was done over $9.6 \mathrm{~km}$ ). Figures $1 a$ and

TABLE 2. Major System Parameters for the Lidar Used for Stratospheric Density Measurements at the Observatory of Haute Provence $\left(44^{\circ} \mathrm{N}, 6^{\circ} \mathrm{E}\right)$

\begin{tabular}{lc}
\hline & Characteristics of the System \\
\hline \multicolumn{1}{c}{ Emitter } & $532 \mathrm{~nm}$ \\
Wavelength & $300 \mathrm{~mJ}$ \\
Energy & $0.1 \mathrm{~nm}$ \\
Linewidth & $15 \mathrm{~ns}$ \\
$\begin{array}{l}\text { Pulsewidth } \\
\text { Repitition rate } \\
\text { Divergence }\end{array}$ & $10 \mathrm{~Hz}$ \\
\multicolumn{1}{c}{ Receiver } & $3 \times 10^{-4} \mathrm{rad}$ \\
Telescope diameter & $0.6 \mathrm{~m}$ \\
$\begin{array}{l}\text { Telescope area } \\
\text { Field of view } \\
\text { (to be reduced) }\end{array}$ & $0.28 \mathrm{~m}^{2}$ \\
$\begin{array}{c}\text { Bandwidth } \\
\text { Receiver gate } \\
\text { In photon counting } \\
\text { mode } \\
\text { In analogical mode }\end{array}$ & $5 \times 10^{-3} \mathrm{rad}$ \\
\end{tabular}
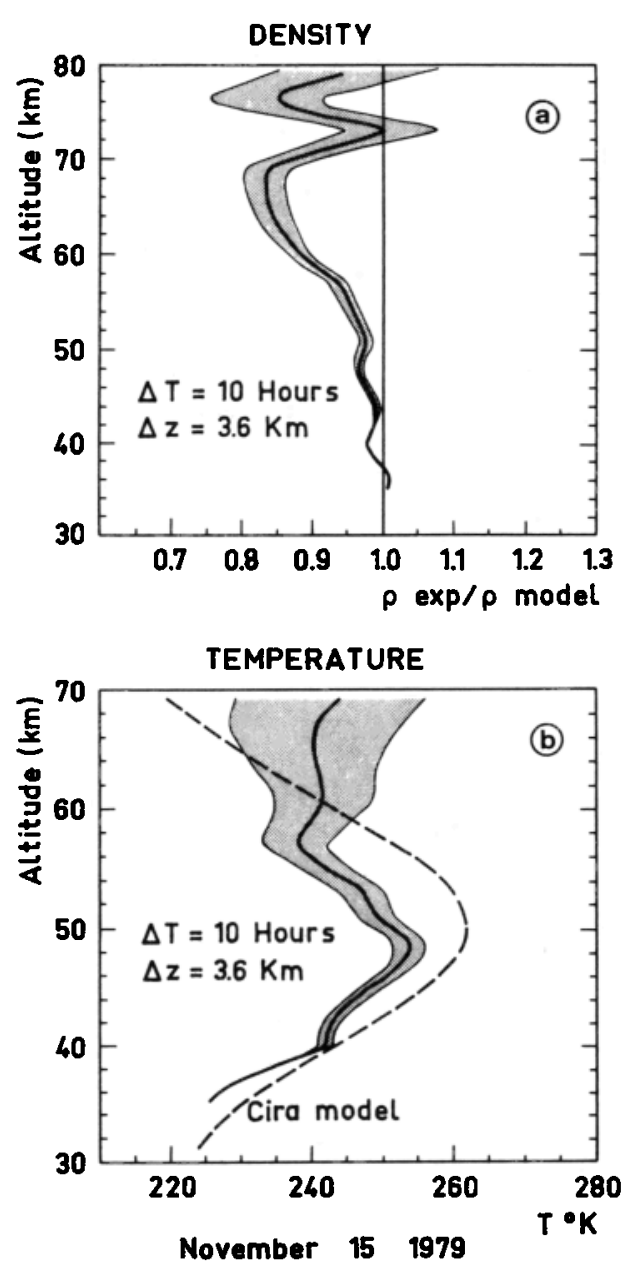

Fig. 1. Density and temperature data for the night of November 15-16, 1979, with 10 hours integration time and a vertical smoothing of the data over $3.6 \mathrm{~km}$. (a) The ratio of experimental density value to CIRA 72 model for November; $(b)$ the experimental temperature profile (solid line) compared to CIRA 72 model (dotted line). The shaded area corresponds to \pm 1 standard deviation.

$2 a$ present two samples of density profile as compared with the adequate CIRA model for November 1979 and August 1980 , respectively. In winter the discrepancy with the model stays within $20 \%$, while the summer profile disagrees by more than $30 \%$ with the model above $70 \mathrm{~km}$. This disagreement may be due to the inadequate position of the altitude of the mesopause in the CIRA model, which is known not to be very adequate for the summer situation.

As described in an earlier publication [Hauchecorne and Chanin, 1980], the atmospheric temperature profile can be computed from the density profile, assuming that the atmosphere obeys the perfect gas law and is in hydrostatic equilibrium. The atmospheric pressure at the upper limit of the measurements $(90 \mathrm{~km})$ is fitted with the CIRA 72 model, and then the temperature in absolute value can be deduced from $80 \mathrm{~km}$ downward to $30 \mathrm{~km}$, even though the density measurements are only relative. The contribution of the extrapolated pressure uncertainty to the temperature value becomes negligible after $10 \mathrm{~km}$. As a consequence the range for the temperature measurements will always be $10 \mathrm{~km}$ lower than for the density. Two examples of temperature profiles are given in Figures $1 b$ and $2 b$ for winter and summer periods. The difference with the CIRA 72 model below the stratopause are, in both 

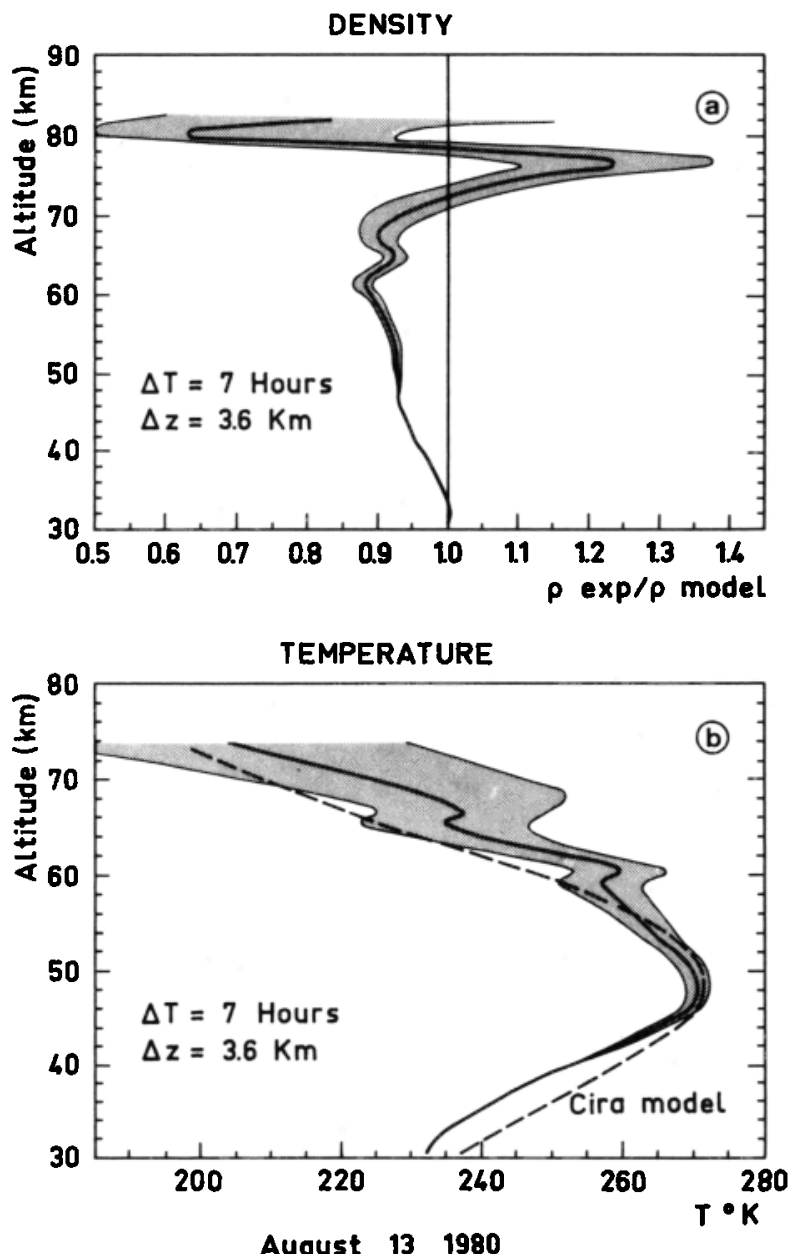

Fig. 2. As in Figure 1 for the night of August 13-14, 1980, and a 7hour integration period.

cases, quite large when compared to the standard deviation and are still significant above the stratopause in Figure $\mathbf{1 b}$.

The density and temperature profiles presented in Figure 1 were obtained with the first lidar station at the lithium reso- nance wavelength $(670 \mathrm{~nm})$, while the data reported in Figure 2 were obtained with the new station at $530 \mathrm{~nm}$. The accuracy in the lower part of the profiles is much improved with the new station, owing to the gain in efficiency mentioned earlier; but the quality of the data is still relatively poor above $60 \mathrm{~km}$ because of the high level of sky background that will be decreased shortly by a factor of 100 after reduction of the field of view.

Density and temperature accuracies with a vertical resolution of $3.6 \mathrm{~km}$ are presented in Figure 3 for the two experimental sets of data presented in Figures 1 and 2, with 10 and 7 hours integration time, respectively. The accuracy, after the above-mentioned improvement, is also presented for 10 hours integration time. The performances of the method for any integration time $T$ can be deduced for this figure as the accuracy will be reduced by $(10 / T)^{1 / 2}$. It should be noticed that the time resolution of the measurement is the object of a trade off with both the height resolution and the accuracy but is not likely to be limited by the repetition rate of the laser (1-10 Hz). With the performances indicated in Figure 3 the lidar technique should become a precious tool to study the thermal behavior of the stratosphere and mesosphere with good temporal and spatial resolution.

Several objections to the use of the method have been neglected in the preceding discussion. One of the most basic is the assumption that between 30 and $80 \mathrm{~km}$ the atmosphere is free of aerosols, which may create a contribution to the backscattered signal by Mie scattering. This question can be cleared up by working with two different wavelengths, as Mie and Rayleigh scattering processes vary very differently as a function of wavelength. Several series of measurements were performed at two different wavelengths $(670$ and $530 \mathrm{~nm})$ and gave simultaneous and very similar density measurements, even during the post Mount St. Helens eruption period, when the level of stratospheric aerosols was much higher than usual. Figure 4 presents the ratio of the two density measurements deduced at the two wavelengths and indicates that the agreement is within the limits of their respective accuracy. But, a spot check at two wavelengths should be performed at regular intervals to rule out a possible contribution of meteoretic dust or clusters at the $80 \mathrm{~km}$ level.
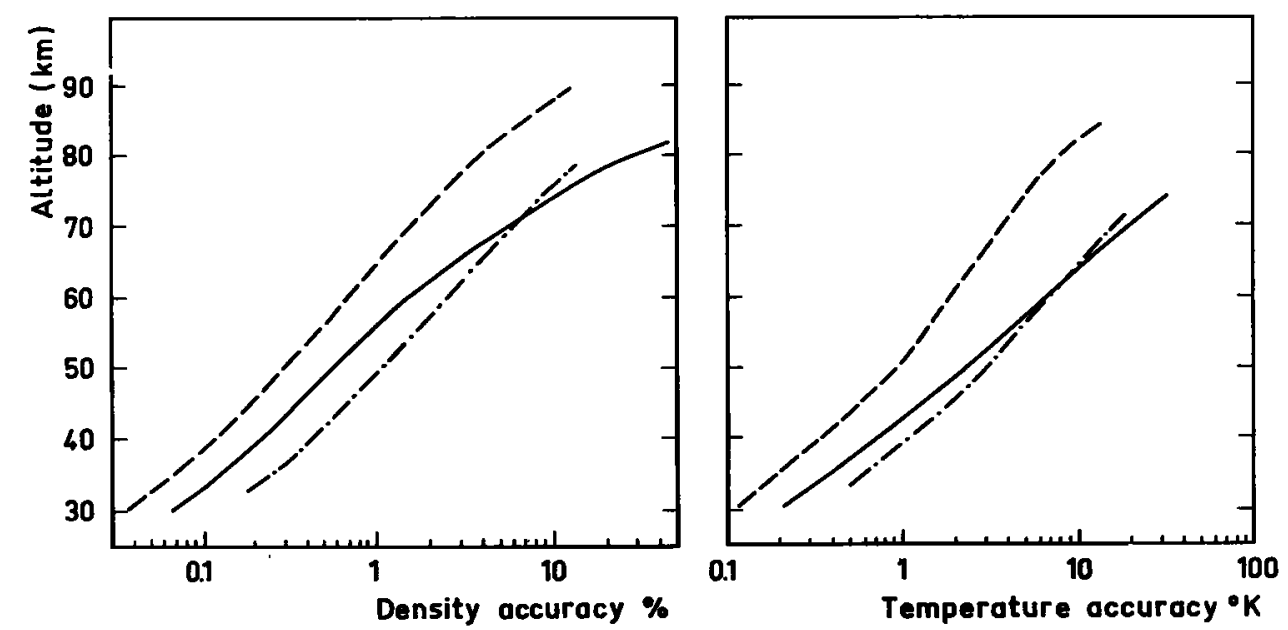

Fig. 3. Density and temperature accuracy as a function of height for $\lambda=670 \mathrm{~nm}, \Delta T=10$ hour (dash-dotted line); for $\lambda=530 \mathrm{~nm}, \Delta T=7$ hour (solid line) as expected at $\lambda=530 \mathrm{~nm}$ and $\Delta T=10$ hours after reduction of field of view down to $5 \times 10^{-4}$ rad. (dotted line). 


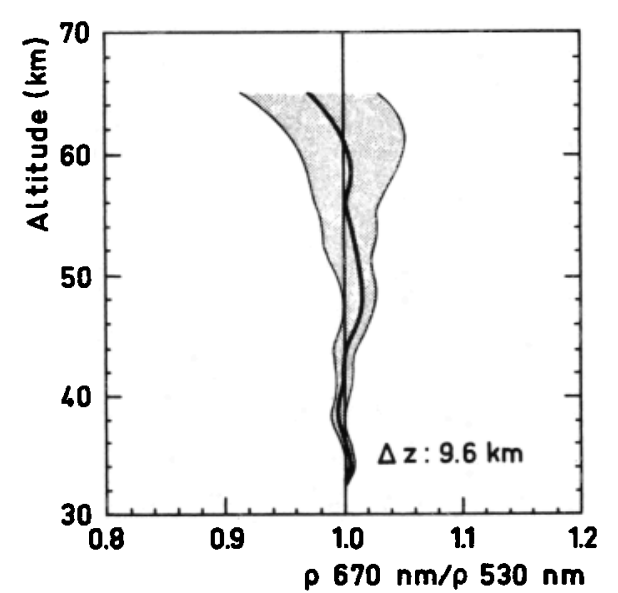

Fig. 4. Comparison between density profiles obtained at 670 and $530 \mathrm{~nm}$ with an integration time of 2 hours and a vertical smoothing over $9.6 \mathrm{~km}$.

The other limits of this method are its restriction to clear weather conditions and to nighttime. There is little to be done about the first limit because the improvement of working at infrared wavelengths $(10.6 \mu \mathrm{m})$ is canceled by a tremendous reduction of range. On the other hand, the restriction of the measurements to nighttime can be overcome. Our group has recently observed the sodium daytime emission with a signalto-noise ratio of 50, and the Rayleigh scattering is then measured up to $50 \mathrm{~km}$. These daytime measurements are still preliminary, but they encourage us in seeking to obtain daytime density and temperature profiles at least up to $50 \mathrm{~km}$ in the near future. This will be valuable for studying wave propagation and diurnal variation of stratospheric temperature.

\section{Evidence of Wave Propagation}

The density profiles presented in Figures 1 and 2 were obtained with an integration time of 10 and 7 hours, respectively. The large difference with the model has a tendency to hide the oscillating structure of the profile. In what follows, to study the temporal behavior of the density profile the experimental data are normalized to the whole night average value $\bar{\rho}$. Wave-like structures appear, then, on all the profiles inde- pendentiy of the season and for any integration time ranging from a few minutes up to a few hours. Figure 5 presents two examples of such profiles: the winter profile (Figure $5 a$ ) obtained at $670 \mathrm{~nm}$ with 2 hours integration time, the summer one (Figure $5 b$ ) at $530 \mathrm{~nm}$ with half an hour integration time. All of the profiles that have been recorded in the last 2 years of measurements exhibit such a wave-like structure. The density oscillates around an average profile with amplitude reaching $5 \%$ of the ambient density at $50 \mathrm{~km}$ and up to $15 \%$ at $70 \mathrm{~km}$. This increase in the amplitude of the perturbation with height is a characteristic feature of all our data. For most of the altitude range up to $70 \mathrm{~km}$, the amplitudes of the density variation are larger than the standard deviation and thus can be considered as significant.

\section{Characteristics of The Wave Propagation}

The improvement in temporal resolution of the density profile has been an important step forward in the study of the wave propagation. The profiles obtained recently (Figures $6 a$, $6 b, 6 c)$ exhibit very well-defined structures indicating clearly a downward propagation of the phase between 40 and $75 \mathrm{~km}$. From this figure we deduce a vertical wavelength of $7.5 \mathrm{~km}$. The amplitudes of the oscillations around the mean density, increasing with height as mentioned before, can be studied as a function of height. From such set of data it has been shown (Figure $6 a$ ) that, between 40 and $70 \mathrm{~km}$, the amplitude varies in $\rho^{-1 / 2}, \rho$ being the ambient density, as expected from atmospheric wave theory. (This condition is necessary for kinetic energy conservation.) From a series of such hourly profiles we have been able to describe some of the characteristics of the waves observed.

To present a global picture for the full periods of observation and to highlight some feature of the wave propagation the density variations are presented as isopleths of perturbations about the mean value calculated for the whole night. Amplitude of the variation has been corrected for the $\rho^{-1 / 2}$ variation in all the following contour maps. Density increases, corresponding to $\rho>\bar{\rho}$, are represented by positive values and are indicated on the maps by the shaded areas, while data corresponding to negative perturbations $(\rho \leq \bar{\rho})$ are indicated by the clear zones. Isopleths of the density perturbations $\Delta \rho$ are plotted by steps of $2 \times 10^{-2}\left(\mathrm{~g} \mathrm{~m}^{-3}\right)^{1 / 2}$ for

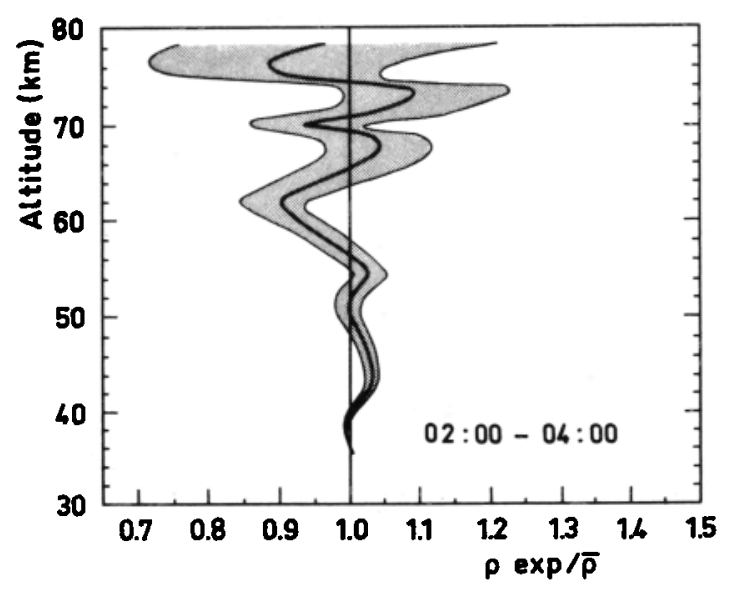

(a) November $16 \quad 1979$

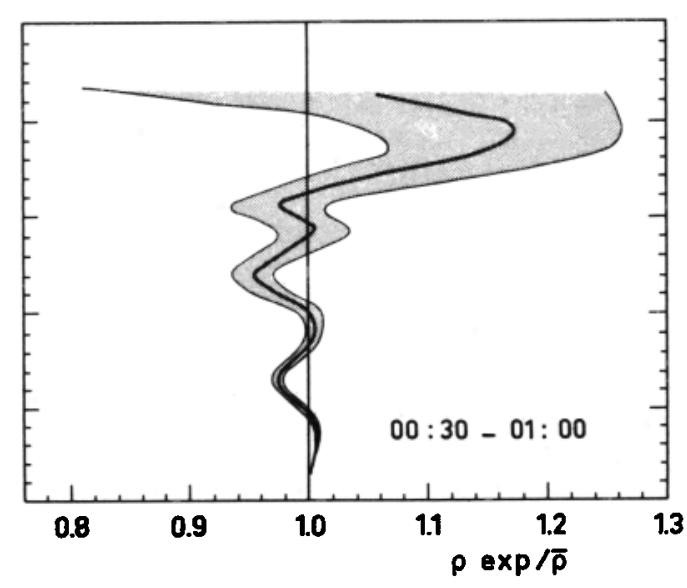

(b) June $27 \quad 1980$

Fig. 5. Individual density profiles $\rho$ normalized to the averaged nighttime density $\tilde{\rho}$. (a) Obtained with 2 hours integration time on November 16, 1980; (b) with half an hour integration time on June 27, 1980. 

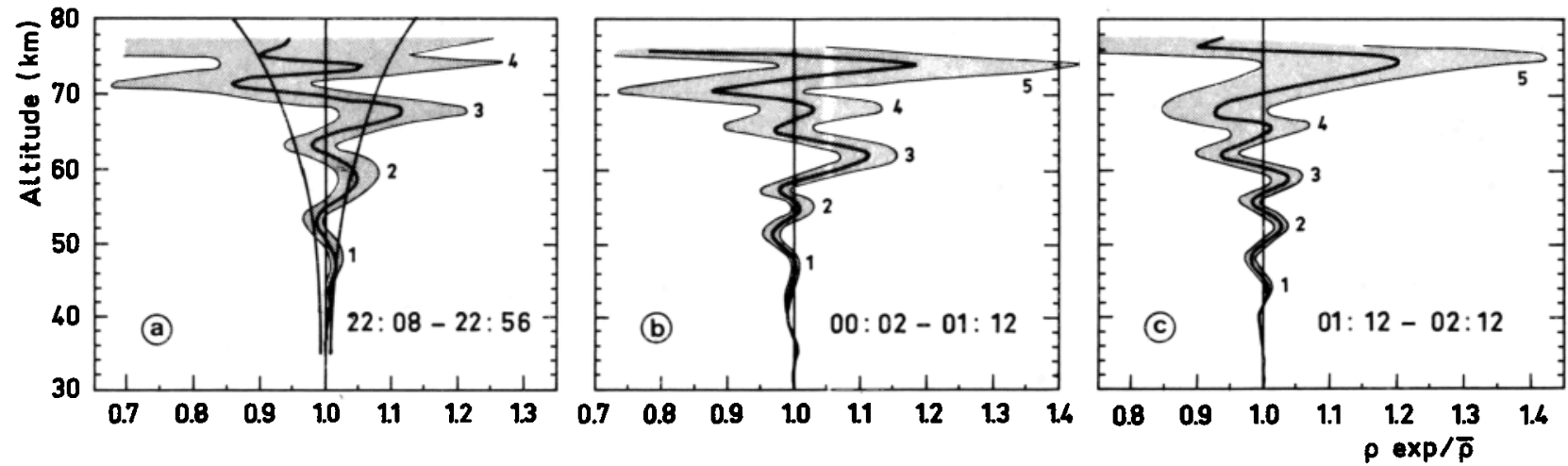

August $13-14 \quad 1980$

Fig. 6. Series of three density profiles normalized to the nighttime profile during the night of August 13-14, 1980. Waves structures are identified and indicated by numbers 1 to 5 . Representation of the $\rho^{-1 / 2}$ law on Figure $6 a$ was calculated with $\Delta \rho / \rho=2 \%$ at $50 \mathrm{~km}$.

the quantity $\Delta \rho \times \rho^{-1 / 2}$. The data presented here correspond to three different periods of the year, November (Figure 7), June (Figure 8), and August (Figure 9), and do not indicate any obvious seasonal variation. It should be mentioned that data obtained during stratospheric warmings have been deliberately excluded because of the influence of planetary wave over powering the influence of gravity waves, and those data are presented in another article [Hauchecorne and Chanin, 1981]. A general feature in all the data is the evidence of a downward phase propagation with a phase velocity varying with height. Between 50 and $70 \mathrm{~km}$ a phase velocity of about 4 $\mathrm{km} /$ hour associated with vertical wavelengths of about $8 \mathrm{~km}$

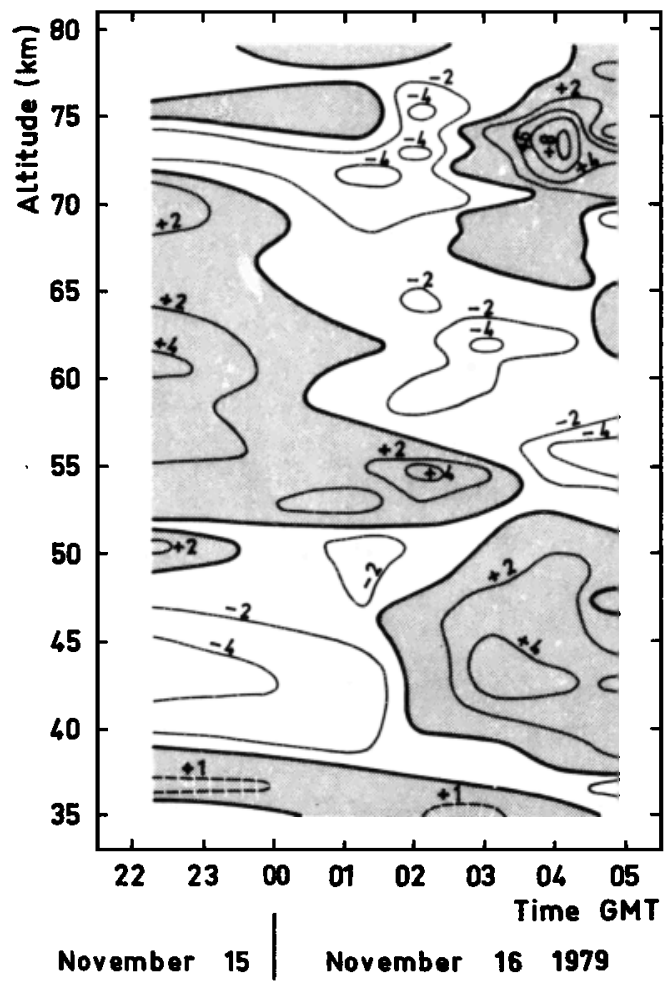

Fig. 7. Map contour of density perturbations from the mean nighttime value for the night of November 15-16. The amplitude of the perturbation is corrected by $\rho^{-1 / 2}$ and contour lines (solid) are plotted by step of $2 \times 10^{-2}\left(\mathrm{~g} \mathrm{~m}^{-3}\right)^{1 / 2}$. The zero perturbation line is represented by a solid heavy line that separates the clear area (decrease of density) from the shaded area (positive perturbations). indicates a 3-4 hour period. From $50 \mathrm{~km}$ downward, the same structures are sometimes present, but, in most cases, they are hidden by a much slower phase descent $(\sim 0.5 \mathrm{~km} / \mathrm{hour})$, half a period during the night, indicating a 24-hour period (Figures $7,8,9$ ). The number of data available to build such maps is still too limited to perform a statistical study of the wave propagation, but the examples presented here give a first indication of the variation of density, and therefore temperature, in the stratosphere and mesosphere on an hourly basis.

More accurate information about the vertical wavelength of the density waves have been derived from the lidar data by using the Fourier analysis technique in the range $30-70 \mathrm{~km}$. The analysis was performed by smoothing the extreme limits of the height range by using a Blackman window to eliminate ghosts. The analysis of $\mathbf{1 0}$ sets of data indicates that most of the time two components are present in the energy spectrum, but the larger part of the spectral energy is always found for vertical wavelengths ranging from 8 to $15 \mathrm{~km}$. The secondary maximum corresponds either to a shorter wavelength in summer (6-8 km) or to a longer one in winter $(20-27 \mathrm{~km})$. As indicated on the two spectra of Figure 10, the relative impor-
(อ)

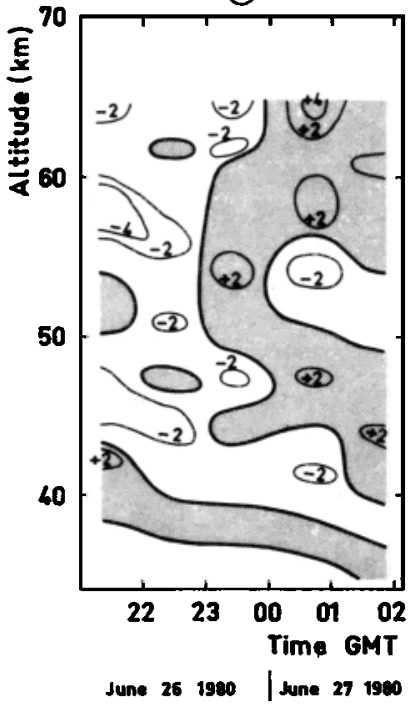

(b)

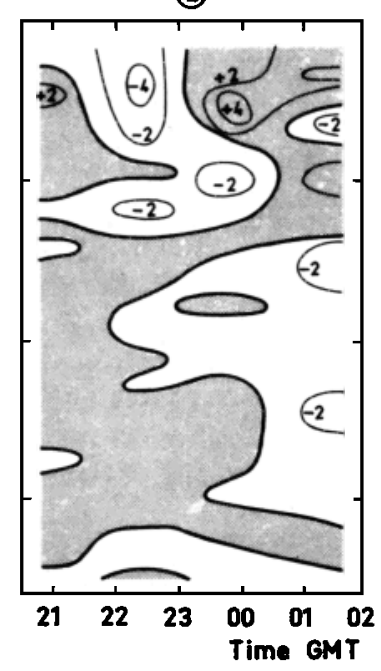

June $281990 \mid$ June 291900
Fig. 8. As in Figure 7 except for the nights of (a) June 26-27, 1980, and (b) June 28-29, 1980. 
(a)

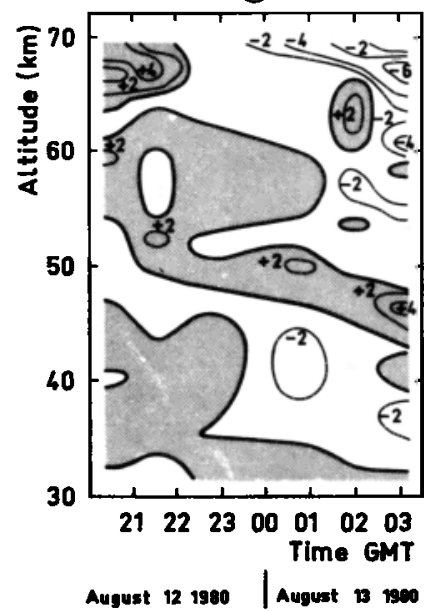

(b)

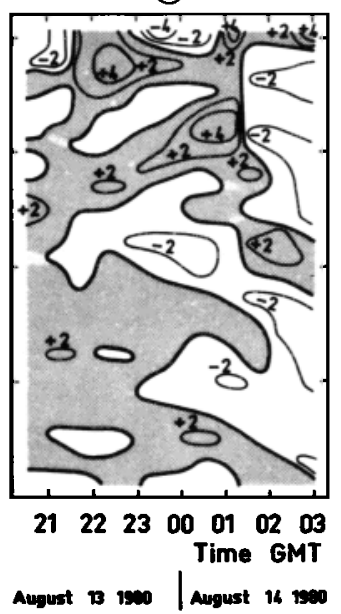

Fig. 9. As in Figure 7 except for the nights of (a) August 12-13 and (b) August 13-14, 1980.

tance of the energy at the two wavelengths is highly variable. In the case of August 12, 1980 (Figure 10a), two vertical wavelengths are sharply defined at 6 and $14 \mathrm{~km}$. On June 26 (Figure $10 b$ ) all the spectral energy is found for a wavelength of $12.5 \mathrm{~km}$, as it can be guessed from the vertical profile represented on Figure $5 b$.

Note that the frequently occurring vertical wavelengths (8$15 \mathrm{~km}$ ) is identical to the wavelengths observed in the vertical motion field in the same altitude range by Weisman and Olivero [1979], even though their data refer to the equatorial region.

\section{Discussion}

Even though the results are preliminary and the data set too limited to allow a statistical study, it appears that two systems of waves are present in this height range: tidal and gravity waves.

The existence of waves propagating upward with a 24-hour period in the altitude range $30-50 \mathrm{~km}$ led us to think that such waves should be from tidal origin. A theoretical calculation of the amplitude and phase of the density variations due to tidal waves was performed to check if the characteristics of the predicted waves would be in agreement with the observations. The calculation was based upon the Lindzen [1967] theory in which the temperature profile was taken from the U.S. Standard Atmosphere. If the 24-hour period wave observed between 30 and $50 \mathrm{~km}$ is to be explained by the diurnal tide, one should expect from the theory a decrease of the density during the night with an amplitude increasing with altitude (forced component of the diurnal tide). Both the average density decrease between 35 and $45 \mathrm{~km}$ ( $\sim 1 \%$ in 6 hours, Figure 9$)$ and the phase (maximum of density at the beginning of the night) are in agreement with the tidal theory. But it should be mentioned that the normalization of the density profiles between 30 and $35 \mathrm{~km}$ may mask the expected density decrease and indicate an artificial phase descent (Figure 8a).

Both phase and amplitude disagree with a tidal model for the 4-4 hour period waves observed above $45 \mathrm{~km}$, but, on the other hand, as it has been shown earlier, the amplitude of those waves obey the $\rho^{-1 / 2}$ law (as expected from internal gravity waves). The range of vertical wavelengths is compat- ible with gravity waves, and the downward phase velocity indicates that the observed variation could be explained by a gravity wave generated in the troposphere and propagating upward. To confirm this hypothesis it is necessary to check whether the characteristics of the observed density perturbations can be explained by internal gravity waves.

From the series of density profiles obtained on August 13, 1980 (Figure 6), the characteristics of such a gravity wave have been completely described and the values of the different physical quantities related with such a wave (wind, energy flux) are in agreement with what is expected in this height range. The whole series of profiles recorded during the night of August 13-14, 1980, from which three profiles are shown on Figure 6 indicates a vertical wavelength of $7.5 \pm 1 \mathrm{~km}$, a phase velocity of $2.2 \pm 0.1 \mathrm{~km} / \mathrm{H}$ leading to a period of $3 \frac{1}{2}$ hours. It was verified on that specific example that between 40 and $60 \mathrm{~km}$, the amplitude of the oscillations was constant if corrected by $\rho^{-1 / 2}$ and the average value of the product $\Delta \rho \times$ $\rho^{-1 / 2}$ was on the order of $2 \times 10^{-2}\left(\mathrm{~g} \mathrm{~m}^{-3}\right)^{1 / 2}$ corresponding to a variation of $2 \%$ of the atmospheric density at $50 \mathrm{~km}$. The increase of the amplitude of the density oscillation above $60 \mathrm{~km}$ will be discussed later.

From those experimental data one can estimate the horizontal wavelength taking into account the simple relationship between the horizontal and vertical wavelengths $\left(\lambda_{x}\right.$ and $\lambda_{z}$, respectively) for such a gravity wave. Assuming a Brunt Vaisala period $T_{B V}$ of $360 \mathrm{~s}$ at $50 \mathrm{~km}$, the relationship
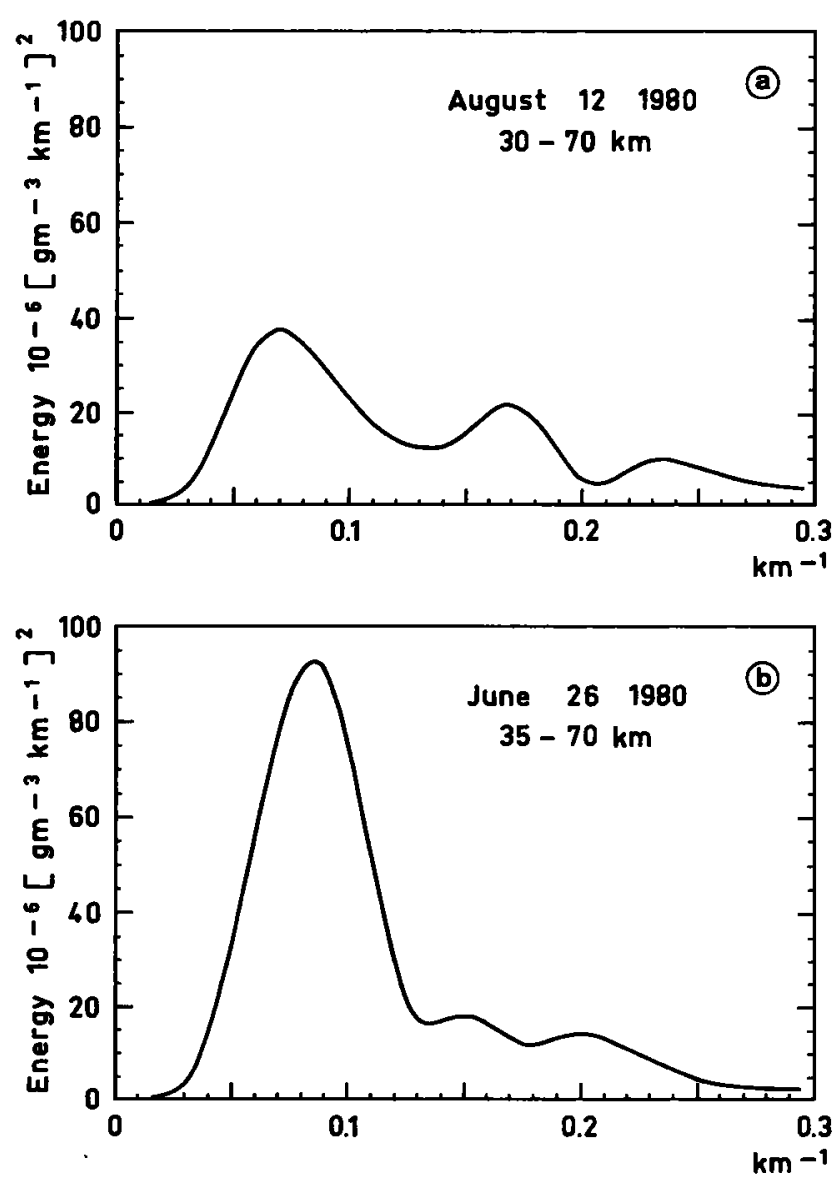

Fig. 10. Spectral energy as a function of the inverse of the vertical wavelength for (a) August 12, 1980, and (b) June 26, 1980 


$$
\frac{\lambda x}{\lambda z} \propto \frac{T}{T_{B V}}
$$

leads to an horizontal wavelength of $260 \mathrm{~km}$. One can also estimate the horizontal wind velocity associated with such a density variation. From Hines [1960], the variation of the horizontal wind component $\Delta_{V}$ and the variation of the density $\Delta \rho$ is given by

$$
\Delta V=\frac{C}{(\gamma-1)^{1 / 2}} \frac{\Delta p}{\rho}
$$

where $C$ is the sound speed $330 \mathrm{~m} \mathrm{~s}^{-1}$ at $50 \mathrm{~km}$ and $\gamma=C p / C_{v}$ is the ratio of heat capacities: $7 / 5$ for the air.

Then it appears that a density variation of $2 \%$ corresponds to a wave-induced horizontal wind velocity of $10 \mathrm{~m} \mathrm{~s}^{-1}$ value that is very reasonable at $50 \mathrm{~km}$ [Groves, 1980].

The the upward propagating energy flux $F z$, can be calculated from the relation

$$
F z=-\frac{1}{2} \rho \Delta V^{2} \frac{\lambda z}{T}=-\frac{1}{2} \frac{C^{2}}{\gamma^{-1}}\left(\Delta \rho \times \rho^{-1 / 2}\right) \frac{\lambda z}{T}
$$

and is found to be equal to $3 \times 10^{-2} \mathrm{~W} \mathrm{~m}^{-2}$ value, which is compatible with the value of $10^{-1} \mathrm{~W} \mathrm{~m}^{-2}$ for the flux coming out of the troposphere, as given by Gossard [1962].

The large amplitude of the density perturbation observed above $70 \mathrm{~km}$ (up to $20 \%$ of the average density) should still be looked at with caution until the accuracy of the measurements in that height range is improved. However, a different atmospheric behavior is not surprising above $70 \mathrm{~km}$ where the upward propagating internal gravity waves may degenerate into turbulence. One should also consider the possible superposition in that height range of gravity wave of thermospheric and tropospheric origins. This aspect should be investigated with data of better quality that are expected in that altitude range in a near future.

\section{CONCLUSION}

Density profiles obtained from lidar soundings have shown systematic wave-like structures. Such density perturbation are interpreted as a superposition of internal gravity waves propagating upward from the troposphere in the altitude range 30 $70 \mathrm{~km}$ and diurnal tides between 30 and $50 \mathrm{~km}$. Propagation of such waves as well as their influence on the atmospheric density and temperature can now be studied on a continuous basis by lidar soundings from the ground.

Acknowledgments. The authors wish to thank C. Fehrenbach, Director of the Haute Provence Observatory, for his hospitality. They are very grateful to all the members of the lidar team of the Service
d'Atronomie for their contribution in collecting the data. This work was supported by D.R.E.T. under contract 77280 and 79442 .

\section{REFERENCES}

Blamont, J. E., M. L. Chanin, and G. Mégie, Vertical distribution and temperature profile of the nighttime atmospheric sodium layer obtained by laser scattering, Ann. Geophys., 28, 833-838, 1972.

Favre, A. C., E. A. Murphy, and R. O. Olson, Atmospheric density temperature and winds measured during Aladdin II, in Space Research XIV, p. 97, Akademie-Verlag, Berlin, 1974.

Gossard, E. E., Vertical flux of energy into the lower ionosphere from internal gravity waves generated in the troposphere, $J$. Geophys. Res., 67, 745, 1962.

Groves, G. V., Seasonal and diumal vairations of middle atmosphere winds, Phil. Trans. $R$. Soc. London, Ser. A, 296, 19-40, 1980.

Hauchecorne, A., and M. L. Chanin, Density and temperature profiles obtained by lidar between 30 and $80 \mathrm{~km}$, Geophys. Res. Lett., 7, $565,1980$.

Hauchecorne, A., and M. L. Chanin, Le Lidar: Un instrument d'étude de la température stratosphérique at mésosphérique, Notes $C . R$. Acad Sci., Paris, 292, 1981.

Hines, C. O., Internal atmospheric gravity waves at ionospheric heights, Can. J. Phys., 38, 1441, 1960.

Jegou, J. P., M. L. Chanin, G. Mégie, and J. E. Blamont Lidar measurements of atmospheric lithium, Geophys. Res. Lett., 7, 995-998, 1980.

Juramy, P., M. L. Chanin, G. Mégie, G. F. Toulinov, and Y. P. Doudoladov, Lidar sounding of the mesospheric sodium layer at high latitude, submitted to J. Atmos. Terr. Phys., 43, 209-215, 1981.

Kent, G. S., and W. Keenliside, Laser radar observations of the $\mathrm{O}_{3}{ }^{\mathrm{w}, 1}$ diurnal atmospheric tidal made above Kingston, Jamaica, J. Atmos. Sci., 32, 1663-1666, 1975.

Kirchoff, V. W. J. H., and B. R. Clemesha, Atmospheric sodium measurements at $23^{\circ} \mathrm{S}, \mathrm{J}$. Atmos. Terr. Phys., 35, 1493-1498, 1973.

Lindzen, R. S., Thermally driven diurnal tide in the atmosphere, $Q . J$. R. Meteorol. Soc., 93, 18-42, 1973.

Lindzen, R. S., Thermally driven diurnal tide in the atmosphere, $Q . J$. R. Meteorol. Soc., 93, 18-42, 1967.

Mégie, G., and J. E. Blamont, Laser sounding of atmospheric sodium: Interpretation in terms of global atmospheric parameters, Planet. Space Sci., 25, 1093-1109, 1977.

Phillbrick, C. R., D. Golomb, S. P. Zimmerman, T. J. Keneshea, M A. Mac Lead, R. I. Good, B. S. Dandkar, and B. W. Reinisch, The Aladdin II experiment, II, Composition, in Space Research XIV, p. 89, Akademie-Verlag, Berlin 1974.

Richter, E. S., and C. F. Sechrist, Jr., Geophys. Res. Lett., 6, 183, 1979.

Rowlett, J. R., G. S. Gardner, E. S. Richter, and C. F. Sechrist Jr., Lidar observations of wavelike structure in the atmospheric sodium layer, Geophys. Res. Lett., 5, 683-686, 1978.

Weisman, M. L., and J. J. Olivero, Evidence for vertical motions in the equatorial middle atmosphere, J. Atmos. Sci., 36, 2169-2182, 1979.
(Received September 30, 1981; revised February 17, 1981; accepted April 13, 1981.) 